\title{
LA TRANSFORMACIÓN DE LA ESFERA FAMILIAR DESDE EL DERECHO DE EXTRANJERÍA ESPAÑOL*
}

\author{
Encarnación LA SPINA \\ DOCTORA EN DERECHO \\ INVESTIGADORA DEL INSTITUT UNIVERSITARI DE DRETS HUMANS \\ UNIVERSITAT DE VALÈNCIA
}

SUMARIO: I. El desarrollo de la vida familiar en la normativa de extranjería. II. El verdadero alcance de la reagrupación familiar: indicadores de transformación para las familias migrantes. II.I La aplicación de criterios de composición versus imposición: la familia querida. II.2 La ausencia de otras formas de reconocimiento: la familia invisible. III. Reflexiones finales. IV. Referencias bibliográficas.

RESUMEN: La articulación legal del derecho a la vida familiar en Derecho de extranjería se rige por una lógica restrictiva cuyo alcance implica una auténtica metamorfosis de las relaciones familiares. De un lado, la ley combina una composición nuclear y dependiente para promover un ideal tipo dominante de familia que resulta abiertamente excluyente de otras realidades familiares existentes en la realidad social. Y de otro lado, neutraliza la diversidad del entorno familiar modulando otras formas de reconocimiento con vistas a instaurar un modelo de familia preferiblemente no conflictivo. Desde una perspectiva critica, este trabajo se centra el verdadero alcance del régimen de la reagrupación familiar previsto en la actual ley de extranjería española atendiendo a aquellos indicadores de transformación que afectan a la protección jurídica de las familias migrantes y al desarrollo de la vida familiar en sociedades multiculturales.

Palabras ClaVE: familia, Derecho de extranjería, metamorfosis, exclusión, conflicto.

ABSTRACT: The legal articulation of the right to family life in immigration law is governed by a restrictive logic whose scope implies a real metamorphosis of family relationships. On the one hand, Law combines nuclear and dependent composition to promote an ideal dominant type of family that is openly excluding other family realities existing in the society. And on the other hand, it neutralizes the diversity of family environment modulating other forms of recognition in order to achieve a family model preferably non-conflicting. From a critical approach, this paper is focused on the true scope of the family reunification rules provided for the current Spanish immigration law according to those indicators of transformation concerning the legal protection of migrant families and development of family life in multicultural societies.

KEYwORDS: family, immigration law, metamorphosis, exclusion, conflict.

* Programa Vali+D Generalitat Valenciana de investigadores en fase postdoctoral APOSTD20II/053. Este trabajo se inscribe en el marco del Proyecto I+D+i del Ministerio de Economía y Competitividad Derechos Humanos, sociedades multiculturales $y$ conflictos, DER 20I2-3I77I así como en el marco del proyecto Consolider Ingenio 2008-00007 «El tiempo de los derechos», financiado por el Ministerio de Educación. 


\section{El desarrollo de la vida familiar en la normativa de extranjería}

Si bien los principales estudios sobre la realidad migratoria advierten de la existencia de dos variables en los procesos de conformación de la vida familiar en inmigración: la emigración en familia y la creación de vínculos familiares en destino ${ }^{\mathrm{I}}$. La construcción de la familia definida por el Derecho de extranjería abarca preferentemente aquellas familias previamente constituidas como tales antes de la migración y que se encuentran fuera del territorio, pero que no realizaron la inmigración de modo conjunto sino de forma separada, reagrupándose posteriormente el resto de sus miembros. Este tipo de conformación familiar comprende diversos supuestos de reunión de las familias en un contexto migratorio: aquel consecuente con la emigración de los padres, trayendo luego a los hijos, la emigración de uno de los dos padres o bien la modalidad de primero uno de los hijos y posteriormente el otro progenitor. E, incluso, aquel que atiende en función del número de miembros reagrupados, si se ha efectuado la reagrupación completa de la familia nuclear o incompleta, atendiendo a una cuestión meramente cuantitativa, puesto que en la distancia y aunando las diversas estrategias transnacionales del cuidado y la afectividad familiar, dicha «unidad» sí existe desde un espacio transnacional ${ }^{2}$.

Independientemente de las peculiaridades de preexistencia y predeterminación del núcleo familiar a reagrupar, el reconocimiento del derecho a la vida familiar para nacionales de terceros Estados ha transitado esencialmente por el marco normativa de extranjería de forma tardía, pues la inmigración era perfilada en términos de política pública y no de intereses privados o derechos, ni para los nacionales ni para los extranjeros. Un tránsito tardío que no ha sido óbice para que la familia migrante fuera ampliamente objeto de interés y control desde el marco normativo de la extranjería y las políticas públicas viéndose incluso obligada a renunciar a su poder de decisión definitiva sobre sus miembros llegando a la supresión de cualquier tipo de preferencia familiar que se quiera hacer valer en la esfera privada.

En cualquier caso, la protección y asistencia que exige la familia por parte del Estado ha sufrido importantes fluctuaciones ante la voluble articulación normativa del instrumento diseñado al efecto, la reagrupación familiar como falso sinónimo de derecho a la vida familiar. Basta recordar como la reagrupación familiar se presenta como un instrumento normativo para que los inmigrantes residentes en el territorio nacional puedan hacer efectivo su derecho a la vida en familia contribuyendo así a su integración social y económica en la sociedad de acogida. Por tanto, presenta una triple condición de mecanismo de entrada legal, derecho fundamental y vía de integración que justifica la voluntad de configurar este derecho

\footnotetext{
${ }^{1}$ GRILLO, R., The family in question. Immigrant and Ethnic Minorities in Multicultural Europe, Amsterdam, Amsterdam University Press, 2008. BALDASSAR, L.; VELLEKOOP BALDOCK, C. AND WILDING, R., Families Caring. Across Borders. Migration, Ageing and Transnational Caregiving, New York, Palgrave Macmillan, 2007.

${ }^{2}$ SUÁREZ-OROZCO, C. AND SUÁREZ-OROZCO, M., «Familyhood across borders», MCLAIN, L.; CERE, D. What is parenthood?: contemporary debates about the family, New York, Newyork University press, 20I3, págs. 279-295.

${ }^{3}$ CARENS, J., «Who should get in? The Ethics of Immigration admissions», Ethics and international affairs, I7, I, 2003, págs.95-IIO, pág. 98.
} 
en su mínima expresión y cierta percepción negativa en el uso de etiquetas tendenciosas como inmigración de arrastre, padecida o falsa $a^{4}$ por varios motivos.

De un lado, su condición de inmigración de arrastre, niega su concreción jurídica como un derecho, por ser un privilegio o recompensa condicionada a una óptima conducta del trabajador migrante residente que mantenga sus familiares en el país de origen y cierta capacidad económica en destino. De otro lado, su condición de inmigración padecida, indirectamente refuerza el temor hacia la dependencia del welfare social, pues la exigencia de capacidad habitacional y económica se reinvierte con cargo al reagrupante así como su posible integración en derechos. Y, por último, su connotación de falsa inmigración, aporta paradójicamente una concepción legal de familia migrante que no sólo no responde a todas las realidades familiares migrantes posibles sino que proyecta desde la generalización $u$ abstracción un ideal inexistente.

Sin duda, la confluencia de estas razones retroalimenta la necesidad de vertebrar normativamente el desarrollo de la vida familiar como forma de gestión controlada del tránsito familiar para los nacionales de terceros Estados, un control que ha sido en el caso español relativamente frenético.

En efecto, basta recordar como inicialmente la Ley Orgánica de Derechos y Libertades de los Extranjeros en España 7/1985 de I de julio dedicaba su título I a los derechos y libertades fundamentales de los extranjeros en España sin prestar atención a la cuestión básica de la reagrupación familiar hasta el artículo 7.2 del Reglamento de ejecución de la Ley Orgánica de Derechos y Libertades de los Extranjeros en España de 26 de mayo de i9865. Sólo con posterioridad, en cumplimiento al compromiso asumido en la reunión del Consejo de Ministros de la Unión Europea de I de junio de I993, se reguló en el nuevo Reglamento de ejecución a la LO 7/1985, Real Decreto 155/1996 de 2 de febrero la condición de derecho a la reagrupación familiar. De hecho, como respuesta al Acuerdo del Pleno del Congreso de los Diputados de junio de $1998^{6}$, en la Ley Orgánica 4/2000 sobre derechos y libertades de los extranjeros en España y su integración 7 , se otorgó por primera vez el tratamiento de derecho a la reagrupación familiar en una doble dirección y con un reconocimiento amplio sólo matizado levemente.

Mientras que radicalmente distinta sería la regulación legislativa que efectúa la LO $8 / 2000^{8}$ de contrarreforma de la Ley Orgánica 4/2000 por medio de un reconocimiento unilateral al extranjero residente y supeditando el derecho al cumplimiento de una serie de

${ }^{4}$ LA SPINA, E., Familias transnacionales, sociedades multiculturales e integración: España, Italia y Portugal en perspectiva comparada, Madrid, Dykinson, 20II.

${ }^{5}$ Vid. art. 7.2 del Real Decreto II9/I986 de 26 de mayo (BOE núm. I40, I2 de junio de I986).

${ }^{6}$ El Acuerdo de la Comisión de Política Social y Empleo relativo al Informe de la subcomisión para estudiar la situación de los españoles que viven fuera, así como de los inmigrantes y refugiados que han llegado a nuestro país conocer a fondo sus necesidades y reivindicaciones prioritarias: proponer las medidas- legales $y$ sociales- que es conveniente adoptar para solucionar los problemas existentes, aprobado por el Pleno del Congreso de los Diputados de 23 de junio de I998. (BOCG de I5 de julio de I998).

${ }^{7}$ La normativa de extranjería española es la Ley Orgánica 4/2000, de II de enero, sobre derechos y libertades de los extranjeros en España y su integración social (en adelante LODYLE), modificada por la Ley Orgánica 8/2000, de 22 de diciembre y la Ley Orgánica I4/2003, de 20 de noviembre (BOE núm 279 de 2I de noviembre de 2003). SOLANES CORELLA, A., «Un balance tras 25 años de leyes de extranjería en España: I985-2010», Revista del Ministerio de Trabajo e Inmigración, 90, págs. 77-IOI. 2000).

${ }^{8}$ Vid. el artículo I6.I y 2 en la redacción dada por La Ley Orgánica 4/2000 (BOE núm. IO, I2 de enero de 
requisitos. Las sucesivas reformas operadas por medio de la Ley Orgánica I4/2003 y la Ley orgánica 2/2009 de II de diciembre junto a su desarrollo reglamentario introducen algunas de las modificaciones significativas en torno a la figura de la reagrupación familiar «para evitar fraudes en las reagrupaciones en cadena» que se ven justificadas por la actual situación de crisis económica y la búsqueda de equilibrio entre capacidad de acogida e integración efectiva9'.

Este frenesí normativo sobre el desarrollo de la vida familiar como mecanismo de regulación de la esfera privada en inmigración hace evidente una clara dicotomía entre la familia que puede ser objeto de reagrupación familiar y aquélla que debería ser admitida como tal de acuerdo a los requisitos previstos por el legislador. El análisis de tales condicionantes permite dirimir el verdadero alcance práctico de la reagrupación familiar por medio de dos indicadores de transformación que equivalen a una profunda transformación de la familia objeto de regulación. Bajo mi punto de vista, una auténtica metamorfosis kafkiana tal y como a continuación se tratará de argumentar.

\section{El verdadero alcance de la reagrupación familiar: indicadores de transformación para las familias migrantes}

A lo largo de los años, la célebre Metamorfosis de Kafka ${ }^{\mathrm{Io}}$ ha inspirado múltiples lecturas e interpretaciones sobre la identidad y alienación del individuo. La recurrente alusión a la metamorfosis más allá del estricto ámbito literario es una clara referencia a un proceso de cambio radical y progresivo en términos parejos a la conocida transformación irreversible del personaje Gregor Samsa en un insecto. Esta conocida transformación en múltiples ocasiones ha permitido reproponer y abordar desde diferentes dimensiones uno los temas centrales de la narrativa kafkiana: el individuo impotente ante una instancia superior, el trato de una sociedad autoritaria hacia el individuo diferente, el aislamiento de esta sociedad y la soledad de las relaciones. Si bien las lecturas han sido profusas, la transformación del protagonista Gregor ha sido claramente identificada como una imagen de la anomia, el extrañamiento y el desarraigo así como por encarnar a la perfección el

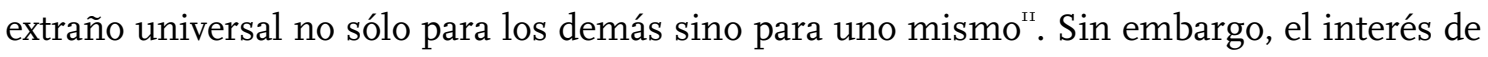
Kafka ha ido más allá de plasmar el absurdo en la modificación del individuo para centrarse esencialmente en la metamorfosis que experimenta paralelamente el protagonista y su familia con motivo de su nuevo aspecto en el desarrollo de la historia.

Durante la historia el protagonista va perdiendo toda condición humana inmerso en un progresivo proceso de extrañamiento por el que vive una existencia condicionada por unas obligaciones hacia su padre - Gregor trabaja para mantener a la familia- y hacia la empresa para la que trabaja. La vida anterior del personaje Samsa se caracteriza por el sometimiento y el cumplimiento servil de las órdenes de quienes ejercían sobre él un poder ilimitado. Con ello, se presenta el planteamiento de la relación existente entre su condición

\footnotetext{
${ }^{9}$ Vid. Ley Orgánica 2/2009 de II de diciembre de reforma de la Ley orgánica 4/2000 (BOE núm. 299 de I2 de diciembre de 2009) que ha entrado en vigor el i3 de diciembre.

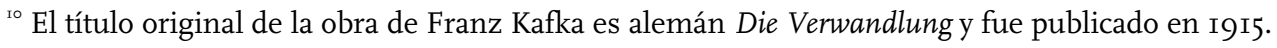

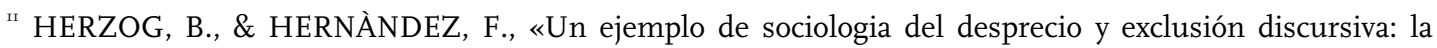
metamorfosis de la familia según Kafka», International and Multidisciplinary Journal of Social Sciences, 2(2),2013, págs. I98-217, pág. 205.
} 
de objeto y su situación como sujeto, dado que el protagonista hasta este momento había sido un objeto útil, indefenso y tras su transformación en insecto ha ido perdiendo, gradualmente, confianza en sí mismo, a la par que descubría su grado de extrañeza en relación con el universo en que vivía. De este modo, hay dos fuerzas en pugna: por un lado, su sentido del deber y de la responsabilidad lo obligan a reintegrarse al trabajo; se siente culpable por lo sucedido y no puede imaginarse su entorno familiar sin su presencia actuante y resolutiva ante todos los problemas que se presentaban. Y, por otro lado, desde su actual perspectiva de animal, de objeto útil, no puede permitir que se le siga utilizando y por eso continua luchando hasta su trágico final. La transformación del protagonista es sin retorno puesto que su condición de insecto es irreversible y no podrá dejar de serlo sin aceptar la opresión y el menosprecio como sujeto. De hecho, a partir de la metamorfosis, el personaje vive el grado de responsabilidad que le corresponde frente a los miembros de la casa y sufre ante la preocupante situación en que quedarán su padre, madre y hermana si él no puede continuar trabajando.

Si trazamos paralelismos entre los movimientos del personaje en el desarrollo de la novela y la articulación legal de la familia propuesta desde el Derecho de extranjería por medio del régimen de la reagrupación familiar, es posible hallar correspondencia entre la imposición de criterios de exclusión para los familiares elegibles y la ausencia de otras formas de reconocimiento que conduce a la opresión y al menosprecio de la familia migrante $^{\mathrm{I} 2}$.

De un lado, la transformación de la composición legal del ámbito familiar desde el Derecho de extranjería ha contribuido a crear una nueva e inédita tipología de relación familiar. Frente a las habituales notas de universalidad y amplitud en los principales documentos de Naciones Unidas sí existen elementos definitorios y explícitos hacía un modelo de familia concreto $^{13}$ como es la definición estricta de familia migrante, dada por el Convenio sobre los Derechos de los Trabajadores Migrantes y sus familiares de i8 de diciembre de $1990^{14}$. Y, de forma similar, en el ámbito regional europeo, sí la hay para la familia de nacionales de terceros Estados que expresamente tiende a ser asimilada a una forma nuclear en el sentido más estricto y reduccionista del término propuesto en la Directiva 2003/86/CE, pese a no existir una noción unívoca de familia ni por parte del Consejo de Europa ni de las instituciones comunitarias ${ }^{15}$.

Y, de otro lado, la ausencia de otras formas de reconocimiento más allá de la proyección del modelo ideal tipo han moldeado o restringido la admisibilidad de ciertas instituciones jurídicas como la kafala, la poligamia y el repudio. Las pautas marcadas por el

\footnotetext{
${ }^{12}$ HONNETH, A., La société du mépris: vers une nouvelle théorie critique, Paris, La Découverte, 2006, págs. 52 55 recoge entre las tres esferas del reconocimiento para la realización del sujeto, el amor, la política-jurídica y social. Nos interesa la política-jurídica «c'est parce qu'un individu est reconnu comme sujet de droits et de devoirs qu'il peut comprendre ses actes comme une manifestation, respectée par tous, de sa propre autonomie».

I3 PERROCHOUD, R., «Family Reunification», International migration: quaterly review, International Organization for Migration, 27 (4) Dec., I986, págs. 509-524. VAN BUEREN, G., «The international protection of family members rights as the 2Ist century approaches», Human Rights Quaterly, vol. I7, I995, págs. 732-765.

${ }^{14}$ Una definición cirscunscrita a los familiares de los trabajadores migrantes documentados a «dos cónyuges casados o dos personas que tengan una relación que, de conformidad con el derecho aplicable, produzcan efectos equivalentes al matrimonio junto con sus hijos solteros menores de edad a su cargo».
}

${ }^{15}$ STALFORD, H., «Concepts of family under EU law, lessons from the ECHR», International Journal of Law, Policy and Family, I6, 2002, págs. 410-434. 
régimen de la reagrupación familiar tratan de contrarrestar el efecto de tales instituciones jurídicas con el propósito de favorecer erróneamente su integración. Y, en definitiva tienen como objetivo controlar el impacto de toda posible interacción normativa derivada de la consideración individual del extranjero en su dimensión de inmigrante como «el otro» y si cabe más respecto de la consideración plural de su «milieu» familiar por ser matriz de conflictos jurídicos ligados a la diversidad. Ambos son claros indicadores de la transformación de la familia migrante desde dos direcciones convergentes.

\section{II.I. La aplicación de criterios de composición versus imposición: la familia querida}

La ley de extranjería siempre ha tratado el ejercicio de la reagrupación familiar de una forma altamente proclive a la limitación de los sujetos elegibles en el curso de acción fijado. Ello, incluso contraviniendo una clara tendencia del Derecho a la hora de equilibrar el margen de permeabilidad de los confines de la familia y modalidad de formación de las relaciones internas ${ }^{16}$. Tal permeabilidad en el Derecho de extranjería se limita forzosamente a la familia en sentido estricto o nuclear, no siguiendo el esquema de la institución sucesoria o de la obligación de alimentos, en la que se agotan los vínculos familiares que son susceptibles de participar de la herencia y de la solidaridad familiar. Al contrario, se genera un perfil determinado de familias, esto es, un modelo ideal y dominante que no responde a todas las realidades familiares migrantes posibles y, lo que es más sorprendente, no se ajusta a la realidad de las nuevas familias ni a la solidaridad familiar prevista por el país de acogida para tutelar la protección y bienestar social de las mismas ${ }^{17}$. Más bien, persiguiendo el ideal para prevenir posibles conflictos, se legitiman ciertas restricciones sobre la llegada, la permanencia, la contención de las políticas sociales así como la eficacia de la integración de los inmigrantes y sus familiares. La dimensión jurídica de la familia albergada en las leyes de extranjería presenta así una definición legal que en palabras de Cossman, reduce el Derecho como el exclusivo aspecto del problema, no el único aspecto de la solución ${ }^{\text {18 }}$. Es una definición anclada en términos ideales creados por el propio Derecho y exigidos a unas relaciones familiares que han cambiado en el espacio tiempo -del pasado al presente- sino también socialmente.

Por ello, en este contexto requieren especial atención los contornos de las familias objeto de la reagrupación familiar prefijados por la ley de extranjería en base a una serie de transformaciones subjetivas y materiales que definen a los sujetos como elegibles bajo el pretexto de recomponer el círculo familiar «apto» y garantizar que en el momento de la solicitud la misma se halla fuera del territorio del país de acogida.

En primer lugar, existe un compendio de transformaciones administrativas que recaen sobre el agente habilitado para proceder a la reagrupación familiar y que plantean la exigibilidad de un periodo de residencia superior a los dos años antes de la solicitud de la reagrupación, la disposición de una vivienda adecuada, así como recursos estables,

${ }^{16}$ FAVRETTO, A. R., Il disordine regolato, strutture, normative e conflitto familiare, Torino, L' Harmattan, I995, pág.6o.

${ }^{17}$ KOFMAN, E., «Family-related migration: a critical review of European studies», Journal of Ethnic and Migration studies. vol. 30, n. 2, 2008, págs. 243-262. BALSAMO, F., Famiglie di migranti. Trasformazioni dei ruoli e mediazione culturale, Roma, Carocci, 2003. 30.

${ }^{18}$ COSSMAN, B., «Family inside/outsider», University of Toronto Law Journal, 44, I994, págs. I-39, esp. pág. 
suficientes o un seguro de enfermedad. Es decir, condiciones todas ellas que acrediten cubrir las necesidades de los miembros de la familia una vez reagrupada sin posible financiación pública. Se exige, por tanto, una calidad habitacional y económica no generalizada a todas las familias en la sociedad de acogida y no dependiente del welfare social. Las opciones admitidas sin perjuicio de críticas cuantitativas son: a) unidades familiares que incluyan computando al reagrupante y al llegar a España la persona reagrupada, dos miembros, exigiendo una cantidad que represente mensualmente el $150 \%$ del IPREM; b) unidades familiares que incluyan, al llegar a España la persona reagrupada, a más de dos personas siendo necesaria una cantidad que represente mensualmente el $50 \%$ del IPREM por cada miembro adicional. En todo caso, el legislador de extranjería precisa que deben avalarse por los medios económicos durante el año posterior a la fecha de presentación de la solicitud, teniendo en cuenta en un año la evolución de los medios disponibles en los seis meses previos a la fecha de presentación de la solicitud. Y que, en el cómputo, los ingresos provenientes del sistema asistencial no pueden ser aportados, pero sí pueden ser tenidos en cuenta los ingresos de otros miembros de la unidad familiar. Al efecto, solo se admiten dos válvulas de minoración: cuando el familiar reagrupable sea menor de edad, cuando concurran circunstancias excepcionales acreditadas que aconsejan rebajar el quantum en base al principio del interés superior del menor y en relación con la reagrupación de otros familiares por razones humanitarias, previo informe favorable de la Dirección General de Inmigración. En términos análogos, es abiertamente cuestionable la igualdad, la seguridad jurídica y la justicia respecto a la vivienda, pues el artículo 55 del Real Decreto 557/20II establece que, en el momento de presentar la solicitud, se debe aportar el informe expedido por los órganos competentes de la Comunidad Autónoma en el plazo de 30 días máximos, en su defecto de la corporación local en el mismo plazo e incluso a falta de ambos por cualquier medio admitido en Derecho.

En segundo lugar, en su dimensión subjetiva hay una definición claramente impositiva respecto a los beneficiarios de la reagrupación familiar y los derechos derivados de la misma, por varias razones. Por una parte, se mantiene el principio de que los familiares se encuentren fuera del territorio del Estado miembro, salvo excepciones previstas por los Estados. Y, por otra parte, aunque se prevé la posibilidad de reagrupar a los descendientes, ésta queda limitada a los hijos menores de edad, ya que los mayores de edad sólo podrán serlo por motivos de salud. Por ello, es importante el margen de libre apreciación de los Estados a la hora de limitar o hacer extensible este núcleo familiar a otras realidades familiares actuales. La reagrupación de ascendientes en línea recta y en primer grado no admite la reagrupación familiar de ningún tipo de familiar colateral, por ejemplo, hermanos en situación de dependencia, si bien sí se enuncia tras la última reforma de la ley de extranjería la posibilidad de equiparar el cónyuge no casado de un país tercero que mantenga con el reagrupante una relación duradera debidamente probada o que constituya una pareja de hecho registrada. Por el contrario, se contemplan limitaciones o presiones facultativas siguiendo las directrices de la Directiva 2003/86/CE con vistas a la exclusión del hijo de reagrupante poligámico, el sometimiento a un examen previo de integración al hijo mayor de I2 años que llegue independientemente del resto de la familia o su exclusión, 
la exigencia de una edad mínima previa a la solicitud de no más de 2I años, y la efectividad de la vida familiar ${ }^{\text {19 }}$.

De igual modo, el planteamiento de máximas excluyentes va más allá de tales coordenadas e implica gran particularidades sobre cada posible vínculo familiar admitido o elegible como familiar.

Respecto al perfil conyugal, se exige la no separación de hecho y de derecho para admitir su reagrupación y se dirimen con rigidez lo relativo a la disolución del matrimonio en el caso de segundas o posteriores nupcias que deberá haber fijado los derechos económicos del cónyuge de buena fe, de los mayores dependientes, de los hijos comunes así como la indemnización respectiva. Todo ello, sin perjuicio del atento régimen de cautelas en torno a la prohibición de matrimonios poligámicos y en fraude de ley. En cambio, sobre la inclusión de la persona que mantenga con el extranjero residente una relación de afectividad análoga a la conyugal, si bien puede ser leída como equiparación respecto al cónyuge en todos los efectos en el artículo $53 \mathrm{~b}$ del actual reglamento de extranjería, se considera que existe relación de análoga afectividad a la conyugal cuando se encuentre inscrita en un registro público establecido a dichos efectos y no se haya cancelado dicha inscripción. O bien por medio de la acreditación de una relación no registrada, constituida con carácter previo al inicio de la residencia del reagrupante en España. Sin duda, la posible inclusión de este tipo de uniones no matrimoniales es novedosa pero tal previsión no está exenta de posibles problemas como la determinación de un concepto unificado o elementos comunes respecto al marco regulativo de las inscripciones registrales de uniones de hecho en cada Comunidad Autónoma.

Un segundo aspecto de la configuración familiar nuclear bajo el criterio de exclusión es la falsa amplitud de la categoría de hijos. La admisión como familiar respecto a los hijos no casados a cargo del reagrupante o de su cónyuge o situación de afectividad análoga, incluso nacidos fuera del matrimonio o de una unión de hecho registrada o no, sólo se refiere a los hijos menores de edad. Por tanto, se excluyen a los mayores de edad, pese a ser dependientes, sin posibilidad de ampliar la franja de edad hasta los 2I años como sí ha sido admitido para los hijos de familiares comunitarios. Por ello, exige un requisito de carácter puramente material, como es que tales hijos estén efectivamente a cargo del reagrupante y otro más controvertido como la prueba del vínculo de parentesco y de edad, implícitamente incluso por medio de las pruebas de $\mathrm{ADN}^{20}$. Ahora bien, la fijación de la edad máxima y la soltería no bastan para determinar que el hijo pueda ser beneficiario de la reagrupación familiar, pues es preciso acreditar el vínculo de parentesco y, para la renovación de la autorización de residencia por reagrupación familiar, también la escolarización obligatoria durante su permanencia en España. Todo ello, sin perjuicio de que, una vez comprobada la relación de dependencia, si el ejercicio de la patria potestad es en solitario o exclusiva, ésta será causa suficiente para hacer posible la reagrupación;

${ }^{19}$ PASCOUAU, Y., Conditions for family reunification under strain. A comparative study in nine EU member states, Bruxelles, European Policy Centre, 20II, pág. I2I.

${ }^{20}$ MCINTOSH, D., «Defining Family: a comment on the Family reunification provisions in the Immigration Act», Journal Law and Social Policy, 3, I988, págs. I04-II5, pág. I08. LA SPINA, E., «DNA testing for Family Reunification in Europe. An exceptional Resource?», Revista Migraciones internacionales, 22, 6, núm. 3, 2012, págs. 39-74. 
mientras que si la patria potestad es compartida, en este caso a quién pretenda reagrupar el menor debe habérsele otorgado y obtenido legítimamente la custodia del mismo.

Ahora bien, de forma concurrente a la minoría de edad, también prevén la discapacidad de aquellos hijos que no sean objetivamente capaces de proveer a sus propias necesidades debido a su estado de salud. La misma opera como causa habilitante para la reagrupación de éste sin limitación de edad, de acuerdo a la ley española, o bien conforme a la ley personal, en suma más flexible. Un supuesto éste que responde a una lógica más bien asistencial, dada la especial situación de dependencia derivada de las delicadas condiciones de salud del hijo, y menos por el vínculo de parentesco propiamente. Esto es, sólo se admite esta posible situación familiar por el artículo I7 apartado c) de la Ley orgánica 2/2009 de reforma de la Ley orgánica 4/2000 que prevé como agrupables con los extranjeros residentes los menores de dieciocho años o «con discapacidad, que no sean objetivamente capaces de proveer a sus propias necesidades debido a su estado de salud», que no sean hijos del solicitante, pero sí tengan la representación legal suya y el acto jurídico del que surgen las facultades representativas no sea contrario a los principios del ordenamiento español, para frenar el reconocimiento de instituciones familiares de acogida.

Completando el círculo familiar entre excluyentes y excluidos, es necesario profundizar sobre la reagrupación familiar de los ascendientes, pues una vez superada la frontera de la familia nuclear, se rige por una cuestión de dependencia y de parentesco que genera una auténtica situación de naufragio de los abuelas/os o suegras/os en la normativa de extranjería ${ }^{21}$. De hecho, la legitimada discrecionalidad de los Estados Parte siguiendo las directrices de la Directiva 2003/86/CE, hace valer varias limitaciones de edad y grado de parentesco que convergen con la existencia de circunstancias justificativas. Por ejemplo, en referencia a las limitaciones de grado de parentesco, la determinación de los ascendientes beneficiarios, en la ley de extranjería española explícitamente opera con relación al primer grado del reagrupante como de su cónyuge, equiparándolo así a lo dispuesto por lo hijos de parejas de hecho del reagrupante. Mientras que, sobre el alcance de esa relación de dependencia, dispone que se entenderá que los familiares están a cargo del reagrupante cuando acredite que durante al menos un año de residencia en España, ha transferido fondos o soportado gastos de su familiar en una proporción que pruebe una dependencia económica efectiva. Esto es, como concreta el artículo 53 e), que representen al menos el 51\% del producto interior bruto per cápita según lo establecido en materia de indicadores sobre renta y actividad económica por país y por el Instituto Nacional de Estadística. A efectos de cierre de la línea ascendente, la Ley orgánica 2/2009 en la letra d) artículo I7, sí incluye la previsión de una edad mínima, que si bien no estaba limitada en la práctica, si era considerada, pues los menores de 65 difícilmente podían probar la dependencia económica o estar a cargo del reagrupante. Este requisito de edad, en este caso a diferencia de los descendientes, una edad máxima, se suma al de la existencia de razones que justifiquen la entrada de este familiar. Por tanto, indirectamente, se presume que la unión de los ascendientes a sus hijos adultos no es habitual por lo que debe ser justificada esta modalidad de familia alargada por razones humanitarias ordinarias y excepcionales.

\footnotetext{
${ }^{21}$ FRESNEDA SIERRA, J., «Redefinición de las relaciones familiares en el proceso migratorio ecuatoriano a España», Migraciones Internacionales, vol. I, n. I, 200I, págs. I35-I44, pág.I36.
} 
Así, sólo excepcionalmente, cuando concurran razones de carácter humanitario, podrá reagruparse al ascendiente menor de sesenta y cinco años si se cumplen las demás condiciones previstas en la ley. La introducción de tal fórmula, tal y como indica el Dictamen del Consejo de Estado 5I5/20II del 7 de abril de 20II, constituye una excepción a un régimen singularmente limitado que resulta poco cuidadoso para articular los mecanismos específicos de acreditación de esas posibles situaciones apoyadas en razones humanitarias. Entre otros, cuando el ascendiente formara parte de la familia ya constituida en el país de origen en el momento en que el extranjero residente obtuvo su autorización; cuando el ascendiente sea incapaz y su tutela sea otorgada por la autoridad competente en el país de origen al extranjero residente o a su cónyuge o pareja registrada; o cuando el ascendiente no sea objetivamente capaz de proveer a sus propias necesidades. E, igualmente, cuando el ascendiente sea cónyuge o pareja del otro ascendiente, siendo este último mayor de 65 años. Los supuestos que avalan la necesidad de apoyo o necesidad familiar plantean una discriminación por razón de edad contraria al principio de igualdad en la ley reconocido por el artículo I4 CE. Básicamente porque el número de años no proporciona ningún dato real acerca de la situación de dependencia del ascendiente ni de su estado físico, pues pueden producirse situaciones de minusvalía sobrevenida en el padre o madre viudos, menores de 65 años y en situación de ausencia de asistencia. La limitación del ejercicio de la reagrupación familiar de los ascendientes revierte negativamente en la protección del derecho al respeto de la vida familiar reconocido en el artículo $8 \mathrm{CEDH}$ pese al amparo de la Directiva y, sobre todo, marca directa e indirectamente la configuración y el desarrollo de las dinámicas transfamiliares ${ }^{22}$.

Por último, también los efectos de la reagrupación familiar constituyen parámetros restrictivos. Una muestra de ello es la posibilidad prevista en el artículo I7 apartado 2 para que los familiares reagrupados sean posibles futuros reagrupantes, léase la posibilidad de ampliar el círculo de familiares ${ }^{23}$. Esta autorización de residencia y trabajo independiente, de acuerdo al artículo 59 del Real Decreto 557/20II de 20 de abril, habilita al cónyuge, pareja de hecho o hijo reagrupado, si éste último tiene I 6 años, a trabajar por cuenta ajena o propia en cualquier parte del territorio español, ocupación o sector de actividad. En primer lugar, más obvia es cuando se obtenga la autorización de residencia y trabajo por cuenta propia, algo que se materializa en que dispone de uno o varios contratos de trabajo de duración mínima, desde el momento de la solicitud de un año y de los que se derive una retribución no inferior al Salario mínimo interprofesional mensual, a tiempo completo por catorce pagas. El nuevo reglamento incluye la previsión de asimilación del vínculo matrimonial y de las parejas de hecho, con la matización del supuesto de cancelación de inscripción o finalización de la vida en pareja. En cambio, la circunstancia más interesante se refiere al cónyuge o pareja de hecho reagrupado víctima de violencia de género o la constancia de indicios en el informe del Ministerio Fiscal ampliado por el RD 557/20II a los supuestos de víctimas de un delito por conductas violentas ejercidas en el entorno familiar. La tramitación de la solicitud tendrá carácter preferente y la duración de la autorización de residencia y trabajo independiente será de 5 años. En cambio, menos margen de maniobra

${ }^{22}$ SAROLEA, S., Droits de l'homme $t$ migrations. De la protection du migrant aux droits de la personne migrante. Collection du centre des Droits de l'Homme de l'Université Catholique de Louvain, Burxelles, Bruylant, 2006, pág. II5.

${ }^{23}$ SOLANES CORELLA, A., «¿Cómo gestionar los flujos migratorios para potenciar la inmigración legal? Un análisis jurídico desde España», Migraciones internacionales, vol. 4, núm. 4, 2008, págs. I36-I72, pág. I46 y ss. 
existe, tras la reforma, respecto de los hijos y menores bajo representación legal del reagrupante, por la que sólo caben dos circunstancias: esto es, haber alcanzado la mayoría de edad y cumplir algunas de las situaciones descritas en el artículo 59.I del reglamento, por lo que en defecto de autorización de trabajo hayan residido durante cinco años en España. Mientras que la única excepción es para los ascendientes, aunque para ello es necesario que su autorización de residencia haya dejado de ser temporal obteniendo la residencia de larga duración, justificando por ende la dependencia económica de su progenitor y la necesidad de su venida a España. Salvo circunstancias muy excepcionales, si el ascendiente tiene a su cargo uno o más hijos menores de edad o que tengan una discapacidad y no sean objetivamente capaces, podrá optar a una autorización de residencia y trabajo independiente o promover la reagrupación de otro familiar.

\section{II.2. La ausencia de otras formas de reconocimiento: la familia invisible}

De momento, el creciente número de familias en las sociedades de acogida y que encarnan un posible encuentro intercultural ${ }^{24}$, ha tenido una contenida visibilidad en las normativas de extranjería ${ }^{25}$. Y parece una cuestión de orden menor la necesidad de afrontar una mayor yuxtaposición con otros modelos culturales de vida familiar que implican la interacción entre sistemas jurídicos del país de origen y el del país donde la familia pretende asentarse. De ahí que el estatuto personal del extranjero no puede dejar de ser valorado como una compleja imbricación de normas sobre la doble pertenencia del individuo, su voluntad de permanencia en el territorio y la plausible conservación de su bagaje cultural respecto a la sociedad de origen ${ }^{26}$.

Ello, básicamente porque algunas de esas diferencias son consideradas significativas, mientras otras resultan irrelevantes ya que como bien indica De Lucas, el problema se presenta a veces de forma simplista en términos de conflicto cultural precisamente sin llegar a definir los límites compatibles. Mientras que en menor medida se parte de la proyección de la multiculturalidad, como un valor o un fin que la democracia debe garantizar para la integración social ${ }^{27}$ de familias que coexisten, se yuxtaponen, se completan o se contradicen ${ }^{28}$. Al contrario, se legitima una diferencia de trato, refuerzo lógico de la ley de extranjería, no advirtiendo que la diferencia de facto -los modelos de familia integradas por personas pertenecientes a distintas razas, culturas, orígenes étnicos y credos religiosos- pueda requerir normativamente un trato o respuesta simplemente diferente ${ }^{29}$.

${ }^{24}$ FOBLETS, M.C., «Europa frente a una creciente diversidad de culturas: análisis crítico de algunos desarrollos yexperimentos recientes en el ámbito del derecho de familia», en RUIZ VIEYTEZ, E.J.; URRUTIA ASUA, G.: Derechos Humanos en contextos multiculturales ¿Acomodo de derechos o derechos de acomodo?, Derechos Humanos I8, Zarautz, Diputación foral de Guipuzkoa, 20IO, págs. I4I-I62, esp. pág. I4I.

${ }^{25}$ BELVISI, F., « Una riflessione normativa per la società multiculturale. L'esempio del matrimonio islamico», Diritto, immigrazione e cittadinanza, 4, 2003, págs. 28-47, esp. págs. 30, 42, 47.

${ }^{26}$ FOBLETS, M.C., Les familles maghrébines et la justice en Belgique (anthropologie jurdique et immigration), Paris, Karthala, I994, esp. pág. 55.

${ }^{27}$ DE LUCAS MARTÍN, J., Puertas que se cierran. Europa como fortaleza, Barcelona, Icaria Antrazyt, I996, esp. págs. 38 y 76.

${ }^{28}$ FLAQUER, L.; MEIL, G. GUILLEN, A.M. ALMEDA, E. ESCOBEDO, A., Políticas familiares en la Unión Europea, Barcelona, Institut de Ciències Politiques i socials, 2002, esp. pág. 34.

${ }^{29}$ POCAR, V.; RONFANI, P., La famiglia e il diritto, Roma, Editori Laterza, 2008, esp. pág. 248. 
Por ello, es oportuno valorar las variables y las formas de acomodación desde el Derecho de extranjería stricto sensu a los contextos familiares en situación de movilidad que se originan no sólo hacia sino en estos países. En definitiva, una acomodación de las diferencias en el régimen de la reagrupación familiar, entendida como una línea divisoria para la admisibilidad de las instituciones jurídicas importadas ${ }^{30}$, que invita a considerar cuáles son las diferencias reales, entre instituciones familiares islámicas como la poligamia, el repudio y la kafala, sin perjuicio de otras reminiscencias culturales de desigualdad de género $^{3 \mathrm{I}}$ fuertemente y socialmente arraigadas.

A modo de ejemplo, la composición del núcleo familiar de acuerdo al artículo i7 de la Ley Orgánica $2 / 2009^{32}$ cuenta con elementos explícitos e implícitos sobre la importancia de contener lo diverso en la llegada y en la posterior presencia integrada del núcleo familiar. El marco normativo de extranjería completado recientemente con el Real Decreto 557/20II por el que se aprueba el Reglamento de la Ley Orgánica 4/2000 tras la reforma de la Ley Orgánica 2/2009 recoge desde la declaración taxativa de no existencia de un matrimonio poligámico o lo que es lo mismo la presencia o llegada de un solo cónyuge no separado de hecho ni de derecho. Siguiendo con la acreditación de que el extranjero casado en segundas o posteriores nupcias sólo podrá reagrupar con él al nuevo cónyuge si acredita que la disolución ha tenido lugar tras un procedimiento jurídico que fije la situación del cónyuge anterior y de sus hijos comunes en cuanto al uso de la vivienda común, a la pensión compensatoria a dicho cónyuge y a los alimentos que correspondan a los hijos menores, o mayores en situación de dependencia. Hasta llegados incluso a hacer más operativos, los entresijos de la acreditación del esfuerzo de integración por medio de los informes de integración, aquellos de arraigo con sus variantes -social, socio-familiar y familiar- o bien de escolarización de los menores como posibles elementos decisivos en el sumatorio de requisitos fijados para la renovación de la autorización de residencia temporal por reagrupación familiar³.

La solución normativa brindada en supuestos de uniones poligámicas se limita a especificar que en ningún caso podrá reagruparse a más de un cónyuge amparándose en el conocido «efecto atenuado» del orden público ya que la ley de extranjería lejos de una negativa absoluta a reconocer cualquier efecto a las uniones poligámicas, preferentemente sólo se preocupa por limitar la reagrupación a un solo cónyuge o pareja de hecho registrada o no ${ }^{34}$. Sin embargo, un análisis sopesado muestra como la clave prohibitiva de la ley de extranjería respecto al matrimonio poligámico obvia que no es una celebración matrimonial obligatoria por la Shâr'ia, sino opcional y no «exageradamente» extendida. Una de las

${ }^{30}$ JAULT-SESEKE, F., Le regroupement familial, Paris, LDGJ, I996, esp. pág. 373.

${ }^{31}$ Por ejemplo, en el caso uruguayo, el divorcio por la sola voluntad de la mujer y la interpretación de la jurisprudencia ecuatoriana de que el marido sólo incurre en adulterio si tiene una relación extramatrionial fija mientras cuando para la mujer basta con que sea esporádica. Vid. BOUZA VIDAL, N., «Inmigración y Derecho internacional privado de la Familia», en ALDECOA LUZARAGA, F. SOBRINO HEREDIA, J.M. (coord.) Migraciones y Desarrollo, Madrid, Marcial Pons, 2007, págs. 485-512.

${ }^{32}$ Vid. en concreto el artículo I7.I a) que expresamente indica que en ningún caso podrá reagruparse a más de un cónyuge aunque la ley personal del extranjero admita esta modalidad matrimonial. Ley orgánica 2/2009 de II de diciembre de reforma de la Ley Orgánica 4/2000 de II de enero, sobre derechos y libertades de los extranjeros en España y su integración (BOE núm. 299 de I2 de diciembre 20I0)

${ }^{33}$ Vid. artículo 6r Real Decreto 557/20II de 20 de abril (BOE núm. IO3 de 30 de abril).

${ }^{34}$ ADAM MUÑOZ, M.D.; BLÁZQUEZ RODRÍGUEZ, I., Inmigración magrebí $y$ derecho de familia, Córdoba, Ed. Universidad de Córdoba, Junta de Andalucía, 2005, esp. pág. I32. 
restricciones previstas por el propio ordenamiento jurídico musulmán consiste en su exclusión a instancia de la esposa en el contenido de los pactos de contrato matrimonial. Se trata de una cláusula de non-remariage, regulada en un importante número de ordenamientos musulmanes, ya sea de forma implícita Siria o expresamente Jordania, aunque su exacto contenido varía de país a país ${ }^{35}$. Por ejemplo, por su importante presencia en España, el caso de Marruecos cuenta con una legislación que ha regulado esta cláusula contractual prematrimonial de forma expresa en el artículo 40 del nuevo Código de Familia $^{3^{6}}$. Se acepta la institución de la poligamia, pero se establecen dos excepciones: no podrán contraer matrimonio con más de una esposa en los casos en los que no van a poder hacerse cargo de todas ellas de forma justa, y en segundo lugar tampoco podrán contraer ulteriores matrimonios si la primera esposa dispone tal condición. Además, el artículo 42 prevé ciertas prácticas de procedimiento dirigidas a garantizar los derechos de defensa de la mujer, como por ejemplo, aquella que obliga al marido a convocar a la primera esposa para solicitarle su consentimiento, así como advertir a la segunda de que ya está casado. Siendo por tanto inadmisible, cuando el solicitante no disponga de recursos suficientes para atender a las necesidades de dos hogares y asegurarles equitativamente el mantenimiento, el alojamiento y las otras exigencias de vida. Y, de igual modo, como segundo control de calidad, cuando su justificación objetiva y su carácter excepcional no se establezca, evitando así el recurso a una poligamia de hecho de naturaleza ilícita.

En cambio, sobre el repudio, la ley de extranjería se ajusta implícitamente a los parámetros estrictos del orden público y de la competencia exclusiva o cuasi exclusiva de los tribunales para el reconocimiento de disoluciones matrimoniales. Ahora bien, el repudio, a diferencia de la poligamia, aún siendo desfavorable en la tradición religiosa, sólo dos países Turquía y Túnez han abolido el repudio marital y la poligamia ${ }^{37}$. En concreto, dos son las cuestiones de interés: la aplicación de un Derecho extranjero islámico o el reconocimiento del acto de repudio pronunciado en el extranjero que es susceptible de vulnerar los principios fundamentales del ordenamiento. Así, tal y como sostiene Quiñones Escámez, siendo tales las cuestiones planteables, surge una cuestión dilemática para rechazar su

${ }^{35}$ Un supuesto similar se produce en Argelia para la admisión de la poligamia, que exista un motivo justificado, la intención de guardar la equidad en el trato de todas las esposas y la obligación de informar previamente a las mujeres implicadas. En cambio, esta posición contrasta con la permisiva solución existente en Egipto, pues la ley no exige condición alguna al marido que desee contratar un matrimonio poligámico, aunque esta cuestión ha sido largamente debatida en el país. La legislación de Túnez y Turquía se presenta como la más cercana a los principios occidentales en la medida en que no se ha limitado a imponer restricciones a la poligamia, sino que ha optado sin más por prohibirla en cualquier caso. Así, se deduce del artículo i8.i del Código sobre el Estatuto personal de Túnez i956, modificado por Ley n ${ }^{\circ}$ 8-70 de 4 de julio de i958 al afirmar taxativamente que la poligamia está prohibida y vid. LOSANO, M.G., La Turchia tra Europa ed Asia: un secolo tra laicismo e Islam, Memoria dell'Accademia delle Scienze di Torino, Classe di Scienze Morali, Storiche e Filologiche, Serie V, Volume 33, Torino, Accademia delle Scienze, 2009, sobre la poligamia en Turquía tras la reforma del Código Civil de 1956 entrado en vigor el I de enero de 2002, vid. pág. 29-40.

${ }^{36}$ Real Decreto n ${ }^{\circ}$ I-04-22 del I2 del mes de Du al-Hiyya del año I424 (3 de febrero de 2004) por el que se promulga la Ley $n^{\circ}$ 70-03 del Código de Familia. Boletín Oficial n ${ }^{\circ}{ }^{1} 84$ del jueves 5 de febrero del 2004.

${ }^{37}$ El Derecho tunecino tras la reforma del Código del Estatuto Personal, otorga la facultad de repudiar tanto al hombre como a la mujer y ha justificado la prohibición de la poligamia por el versículo del Corán que obliga al marido a tratar por igual a sus esposas, lo que equivale a aconsejar la abolición de la institución. Los otros países se han limitado a establecer tímidas reformas destinadas a reglamentar la publicidad, los efectos del repudio o a ampliar las causas de disolución del matrimonio a petición de la mujer. 
eficacia: su contrariedad al principio de igualdad entre hombre y mujer o una comprobación case by case que implique conocer la institución del repudio ${ }^{38}$.

El repudio, constituye un privilegio del marido, a excepción del ejercitado por la esposa cuando la misma tiene esta opción consignada en el contrato de matrimonio mediante el pago de una compensación económica al marido producida por mutuo acuerdo. En el derecho musulmán tradicional o clásico este privilegio marital, además de su carácter revocable en sus dos primeras formulaciones es irrevocable cuando la fórmula prescrita se haya pronunciado por tercera vez. Por otra parte, las respectivas legislaciones de los Estados musulmanes, a excepción de Túnez, en principio reconocen, tal y como prescribe la Sharía, el derecho del marido a repudiar a la mujer aunque lentamente se han introducido algunas limitaciones al derecho absoluto del varón, exigiendo el cumplimiento de algunas formalidades. Tal es el caso de la mudawanna marroquí, revisada en 2004, según la cual la mujer puede pedir ser repudiada por el marido, con la finalidad de simplificar la desvinculación, sin que en tal caso sea necesario probar la causa ${ }^{39}$.

Tal obligatoriedad de un «procedimiento jurídico» acreditativo de la disolución matrimonial y la exigencia de garantías para la situación jurídica posterior de las personas a cargo, muestra como la actual normativa de extranjería sigue manteniéndose alejada de la pluralidad familiar. La interpretación normativa más contenida y más clara tras el desarrollo reglamentario al hablar acertadamente de disolución del vínculo matrimonial -léase actos voluntarios de los contrayentes como el divorcio y la nulidad matrimonial- produce como efecto en el ordenamiento jurídico la suspensión de la vida en común y el cese de la posibilidad de vincular bienes del otro cónyuge en el ejercicio de la potestad doméstica. De igual modo, una apuesta continuada -si se me permite obstinada- por la amplitud de la prueba diabólica no sólo de la separación de derecho sino de hecho del artículo I7.I a), no permitiría un numerus apertus de figuras jurídicas no contempladas en nuestro derecho interno ${ }^{40}$. Esto es, como válvula de escape del divorcio privado o el repudio revocable o irrevocable, estas últimas erróneamente consideradas idénticas por lo que cabe afirmar que los efectos jurídicos del matrimonio ya no existen y no meramente han sido suspendidos unilateralmente o por mutuo acuerdo sine $d i e^{4 x}$.

En cambio, la kafala resulta una cuestión menos controvertida en términos de un tratamiento igualitario entre hombre y mujer, pero plantea igual número de interrogantes en este mismo plano como institución de cuidado de los huérfanos por medio del acogimiento real por el kafil (necesariamente un varón) de un niño denominado makfoul,

${ }^{38}$ Vid. QUIÑONES ESCÁMEZ, A., «La disolución del matrimonio: especial referencia al repudio islámico » en RODRÍGUEZ BENOT, A., La multiculturalidad: especial referencia al Islam, Madrid, Consejo General del Poder Judicial, 2002, págs. 26I-342, esp. pág. 265-266.

${ }^{39}$ SOTO MOYA, M., «Mujer inmigrante marroquí: reagrupación familiar», en RUIZ SUTIL, C. Y RUEDA VALDIVIA, R., (coord.): La situación jurídico-familiar de la mujer marroquí en España, Sevilla, Junta de Andalucía. Instituto de la Mujer, 2008, págs. I3I-I54.

${ }^{40}$ Aunque como bien apunta ABARCA JUNCO, A.P. y VARGAS GÓMEZ URRUTIA, M., «Artículo I7. Familiares reagrupables», en ESPLUGUES MOTA, C., Comentarios a la Ley de Extranjería, Valencia, Tirant Lo Blanch, 2006, págs. 447-492, esp. págs. 452-466, si se admite esta interpretación amplia, en ningún caso podrá reagruparse más de un cónyuge y partiendo de la noción de cónyuge, que es la que emplea no hay una relación equivalente con el conviviente habitual (pareja de hecho).

${ }^{41}$ ADAM MUÑOZ, M.D.; BLÁZQUEZ RODRÍGUEZ, I., Inmigración magrebí $y$ derecho de familia, cit., esp. pág. 37 . 
declarado abandonado o entregado por su madre o padre a una familia ${ }^{42}$. Sus efectos son mucho más limitados que los atribuidos a la adopción al ser una especie de acogimiento familiar o prohijamiento constituido ante autoridad pública ${ }^{43}$. La kafala no cuenta con una normativa específica dedicada a ella, pero si dos modalidades disímiles en efectos: una constituida respecto de un menor abandonado por medio de una declaración judicial previa de abandono y de un procedimiento que termina con la resolución dictada por el juez de Tutelas contra la cual cabrá recurso de apelación. Mientras que otra modalidad no precisa la intervención del juez y se constituye no respecto de un menor abandonado, dado que no existe declaración de abandono ni sentencia y el menor tiene filiación conocida. En estos supuestos son los propios padres los que entregan a su hijo al kafil y lo hacen de una manera privada, mediante un acta adular por ello es conocida como kafala notarial ${ }^{44}$.

Con relación a estas modalidades, el legislador español y algunos autores ${ }^{45}$, estiman incluidas las instituciones protectoras de los menores e incapacitados existentes en los diversos ordenamientos jurídicos que otorguen al reagrupante ambas funciones o una de ellas. Para ello, rige la exigencia la acreditación de la norma de derecho extranjero en la que esa realidad jurídica se establezca o bien la resolución de atribución de dicha representación, cuya prueba deberá ser valorada por el Tribunal. Así lo pone de relieve la Instrucción DGI/SGRJ/06/2007 sobre la kafala, que actualiza ciertas referencias de una Instrucción anterior de I de diciembre de 2004 con consecuencias jurídicas diversas según si ha intervenido o no en el proceso la autoridad pública y los padres biológicos ${ }^{46}$. Se diferencia en el primer supuesto, la entrada del menor seguirá lo dispuesto en el equivalente al artículo i94 del actual Reglamento de ejecución de la Ley de extranjería que regula el régimen aplicable a los programas de desplazamiento temporal de los menores extranjeros. Mientras que en el segundo supuesto recibe un tratamiento diferente, sobre la base de considerar que en este tipo de kafala, el kafil asume la tutela prevista por el Derecho marroquí, esto es, la tutela dativa, lo que lleva a entender que el kafil es en realidad representante legal del menor marroquí. Esta norma en su última modificación por Ley Orgánica 2/2009 artículo I7.I c) introduce una precisión más, quizás un tanto innecesaria según Diago ${ }^{47}$, al disponer que serán familiares reagrupables: los menores de dieciocho

${ }^{42}$ No es el caso del Derecho marroquí que sí cuenta con la Ley n I5-OI, relativa a la kafala de los menores abandonados y que viene a sustituir a una ley anterior la $\mathrm{n}^{\circ}$ I-93-I652I relativa igualmente a los menores abandonados. Si bien en el Code du statut personnel et successoral de Marruecos no hay previsión de la kafala, en el dahir portant loi n ${ }^{\circ}$ I-93-I65 del io de septiembre de I993 y en la más reciente d.p.l. nº I-02-I72 del I3 de junio de 2002 es catalogado como «prise en charge des enfant abandones».

${ }^{43}$ Vid. entre otras la resolución de la DGRN I4 de mayo de 1992 ha sostenido de manera absoluta que la misma «... no guarda ningún punto de contacto con la adopción reconocida en el ordenamiento español: no supone vínculo de filiación ni de parentesco entre los interesados; no implica alteración del estado civil de éstos, y sólo alcanza a establecer una obligación personal por la que el 'adoptante' se hace cargo del 'adoptado' y ha de atender a sus necesidades y manutención...».

${ }^{44}$ DIAGO DIAGO, P., «La kafala islámica en España», Cuadernos de Derecho Transnacional, Vol. 2, No I, 20IO, págs. I40-I64, esp. pág. I45.

${ }_{45}$ MOYA ESCUDERO, M.: «Derecho a la reagrupación familiar (arts. I6,I7,I8 y i9)», en MOYA ESCUDERO, M. (coord.), Comentario sistemático a la Ley de extranjería (LO 4/2000 y LO 8/2000), Granada, Comares, 200I, págs. 673- 707, esp. pág. 694. Vid. los comentarios de la misma autora a la sentencia de la Audiencia Provincial de Granada de 25 de abril de I995, en Revista Española de Derecho internacional, 47, I995, pág. 4I5.

${ }^{46}$ En contra de ello, y a favor por consiguiente de un tratamiento igualitario vid. ARCE JIMÉNEZ, E., «La kafala marroquí y la legislación de extranjería», Revista de Derecho Migratorio y Extranjería, n I3, 2006, págs. 267-278, pág. 272.

${ }^{47}$ Vid. DIAGO DIAGO, P.: La kafala islámica en España, cit., esp. pág. 22. 
años y los mayores de esa edad que no sean objetivamente capaces de proveer a sus propias necesidades, debido a su estado de salud, cuando el residente extranjero sea su representante legal y el acto jurídico del que surgen las facultades representativas no sea contrario a los principios del ordenamiento español. Nada se indica para aliviar la carga probatoria, como si ocurre con la acreditación de las parejas de hecho no registradas, sobre «la posible utilización de cualquier medio de prueba admitido en Derecho, aunque tendrán prevalencia los documentos emitidos por una autoridad pública ${ }^{48}$.

Por ello, el tratamiento jurídico atípico de esta cuestión en extranjería por la vía de remisión a una instrucción ministerial, más bien debería tender a garantizar si el menor el derecho a una vida familiar normal, consagrado en el artículo 8 del Convenio Europeo sobre Derechos Fundamentales y atender a tales solicitudes de modo positivo, expeditivo y humanitario amparando los intereses del menor. Básicamente porque una fiscalización estricta de la inexistencia de lazos familiares efectivos (menor sin filiación) o la preexistencia de éstos (kafala intrafamiliar) para limitar la sospecha de «kafalas blancas» destinadas a defraudar las normas de reagrupación familiar, pueden ser ciertamente contraproducentes ${ }^{49}$.

\section{Reflexiones finales}

Más allá de cuestionar la existencia de la familia nuclear, considerándola meramente ficticia, tal y como señala $\mathrm{McGlynn}^{50}$ la pretendida inocuidad de una ideología dominante sobre la familia es una muestra más del impacto de la ley en la ordenación de las relaciones familiares en inmigración. Respecto a las familias migrantes hay una clara regresión en la deslegalización de la familia dado el interés apremiante en controlarlas cuantitativamente. Una voluntad que desde el Derecho de extranjería alcanza la configuración del modelo de familia apto para el ejercicio de la reagrupación familiar. Y, en consecuencia legitima una definición más normativa que descriptiva, puesto que más nacionales y no nacionales viven en familias que no se ajustan a un normative ideal. Sin embargo, pese a esta contrastada evidencia, las políticas sociales y legales siguen basándose en dicho concepto excluyendo y discriminando potencialmente ciertas dinámicas familiares para así crear una dislocación entre la familia legalmente admitida y las realidades familiares existentes en inmigración.

De modo especial, el Derecho de extranjería ha instrumentado el régimen de la reagrupación familiar para no sólo no permitir una legítima disyuntiva en la libertad individual de definir o no el proyecto familiar que rija las relaciones interpersonales, sino para reacomodarlo en base a parámetros impositivos o restrictivos totalmente desnortados de la experiencia y realidad migratoria. Una realidad que en cambio se encuentra envuelta en paisajes familiares disímiles, rupturas culturales y afectivas, comportando per se la constante redefinición y reorganización de los retículos familiares, en particular modo para

\footnotetext{
$4^{8}$ Vid. artículo 53 Real Decreto 557/20II de 20 de abril (BOE núm. I03 30 de abril de 20II).

${ }^{49}$ Un estudio detallado de la kafala en QUIÑONES ESCAMEZ, A., «La protección del menor venido a España en kafala: acogimiento con tutela dativa, y en su caso, adopción», en QUIÑNONES ESCÁMEZ, A.;RODRÍGUEZ BENOT, A.; ZEKRI,H., OUHIDA, J., Kafala y adopción en las relaciones hispano-marroquíes, Madrid, FIIAP, 2009, págs. I57-I97, esp. pág. I65.

${ }^{50}$ MCGLYNN, C., «Family reunion and the Free movement of persons in European Law», International Law Forum du droit international, 7, 2005, págs. 159-166. pág. 35.
} 
las relaciones hombre-mujer, madre-padre y padres e hijos o los efectos de la desterritorialización. Las familias quedan expuestas a insensibles interferencias legales en su reestructuración hacia lo ideal como sinónimo de no conflictivo, admitiendo así la lógica de que algunos núcleos familiares tengan más facilidades para reagruparse; mientras que otros, cuya familia no obedece al patrón de familia nuclear, se vean obligados a reconstituir la familia solo con la familia que consiguen o puedan reunir de acuerdo a los parámetros legales.

Por ello al igual que en la metamorfosis de Gregor Samsa es posible observar la secuenciación de diversas transformaciones sustantivas que dan cuenta como el Derecho de extranjería resta importancia sobre hasta qué punto se puede ver mermada la esfera privada del inmigrante a la hora de determinar cuales son los familiares susceptibles de ser reagrupados. Y, también la operatividad de un mínimo margen de maniobra para que él mismo decida con quiénes quiere compartir su vida. El motivo intrínseco radica en el temor de promover una ilimitada elección a la carta o un criterio aperturista pese a quebrar todo equilibrio coherente entre las dos dimensiones pública y privada del desarrollo del derecho a la vida familiar. La primera, legitimada por los intereses generales (orden público, bienestar social) y, la otra, la privada, que como tal no debe perder su esencia, evitando las posibles injerencias del Estado y de la sociedad respecto al individuo.

La excesiva rigurosidad de la normativa de extranjería en la esfera familiar se suma a las dificultades sociales y políticas que tienen el inmigrante en el acceso a una vivienda adecuada, la disponibilidad de unos recursos económicos, el acceso al mercado laboral, el ejercicio de un amplio spectrum de derechos de participación ciudadana o más bien de decisión sobre la prioridad de necesidades sociales. De hecho, cualquier iter procedimental no negociable del régimen de la reagrupación familiar, ya bien de grado de proximidad de parentesco, edad, dependencia, estado civil, no hace más que minimizar o comprimir el ámbito de decisión del solicitante y subordinar sus necesidades sociales como familia. Así la esfera privada del inmigrante queda irreversiblemente atrapada en un laberinto jurídicoadministrativo llamado reagrupación familiar que no atiende a la importancia de ciertas circunstancias internas (fases de la trayectoria migratoria, proyecto migratorio futuro, diferencias culturales, capacidad de renta y de ahorro del inmigrante) y externas (la crisis económica, las características del mercado inmobiliario, los fenómenos de discriminación y el acceso a los derechos sociales). No hay más preocupación por parte del Derecho de extranjería que ver cumplida preceptivamente la autorización de residencia cualificada y ver garantizada la disponibilidad de los medios económicos o habitacionales suficientes para ameritar el acceso a los beneficios del sistema del welfare así como su integración efectiva.

De igual modo, esta injusta dislocación entre la familia legalmente admitida y las realidades familiares existentes se percibe en la invisibilidad de ciertas familias migrantes como consecuencia de la fuerza impositiva y catalizadora del conflicto jurídico transfronterizo por parte del Derecho. La seguridad jurídica se determinan por métodos normativistas tradicionales y no por la acomodación a las exigencias y aspiraciones de las personas que viven en una realidad social en constante cambio. Las soluciones ofrecidas por el Derecho de extranjería, eluden la dimensión relacional de la familia y el individuo particular por medio de la conservación o rechazo de la propia identidad jurídica y cultural.

Por tanto, es prioritario reconocer por parte de los operadores jurídicos en qué medida las respuestas normativas al axioma «la familia significa diferentes cosas para 
diferentes personas» desde el inclusivismo y la tesis del pluralismo indiferente y neutralizante, rechazan una visión crítica sobre la intersección entre la multiculturalidad y los derechos humanos ${ }^{5 \mathrm{I}}$. Es una opción que regirá las otras, porque los miembros de la familia tienen el derecho de mantener y reconstruir la unidad familiar con aquellos que según el ordenamiento del país de origen están unidos por vínculos de convivencia para garantizaría la personalización y autonomía de las elecciones.

Y, de igual modo, es recomendable adoptar con celeridad alternativas plausibles, a mi modo de ver, la admisión de una cláusula que indicara «otros posibles familiares que el reagrupante acredite como tales y con los que precise agruparse», flexibilizar los requisitos administrativos siguiendo el criterio de progresividad de los derechos sociales y reforzar la igualdad en el ejercicio del derecho a la reagrupación familiar desligándolo de la concepción de mero mecanismo de entrada legal sujeta a la soberanía del Estado.

De lo contrario, más bien se seguiría asentando un marco jurídico de corte asimilacionista fundamentado por el exclusivismo según el cual existe sólo una familia y por consiguiente negando posibles variables en la protección de los derechos de ciertos individuos dentro del núcleo familiar especialmente menores de edad, mujeres y ancianos. Sin duda, una opción temeraria que pone en riesgo el mínimo de justicia material que el Derecho debería garantizar para el sujeto que quiere integrar en la sociedad y no hace sino cuestionar la función social del Derecho a la hora considerar el conflicto y darle la solución -insisto- jurídicamente más adecuada.

\section{Referencias bibliográficas}

AbARCA JUNCO, A.P. y VARGAS GÓMEZ URRUTIA, M., «Artículo I7. Familiares reagrupables», en Esplugues MotA, C., Comentarios a la Ley de Extranjería, Valencia, Tirant Lo Blanch, 2006, págs. 447-492.

AdAm MuÑoz, M.D., BlÁZquez Rodríguez, I., Inmigración magrebí y derecho de familia, Córdoba, Ed. Universidad de Córdoba, Junta de Andalucía, 2005.

ARCE JIMÉNEZ, E., «La kafala marroquí y la legislación de extranjería», Revista de Derecho Migratorio $y$ Extranjería, $\mathrm{n}^{\circ} \mathrm{I3}, 2006$, págs. 267-278.

Baldassar, L., Vellekoop Baldock, C. y Wilding, R., Families Caring. Across Borders. Migration, Ageing and Transnational Caregiving, New York, Palgrave Macmillan, 2007.

BALSAMO, F., Famiglie di migranti. Trasformazioni dei ruoli e mediazione culturale, Roma, Carocci, 2003.

BELVISI, F., « Una riflessione normativa per la società multiculturale. L'esempio del matrimonio islamico », Diritto, immigrazione e cittadinanza, 4, 2003, págs. 28-47.

BouZA VIDAL, N., «Inmigración y Derecho internacional privado de la Familia», en AldeCoA LuZARAgA, F., Sobrino Heredia, J.M. (coord.) Migraciones y Desarrollo, Madrid, Marcial Pons, 2007, págs. 485-512.

CARENS, J., «Who should get in? The Ethics of Immigration admissions», Ethics and international affairs, I7, I, 2003, págs. 95-110.

Cossman, B., «Family inside/outsider», University of Toronto Law Journal, 44, I994, págs. I-39.

De Lucas Martín, J., Puertas que se cierran. Europa como fortaleza, Barcelona, Icaria Antrazyt, 1996.

${ }^{51}$ SOLANES CORELLA, A., «Human rights and Conflicts in European Multicultural societies», Migraciones Internacionales, vol. 7, núm. I, págs. 70-Ioo, pág. 76. SUSÍN BETRÁN, R., Fronteras y retos de la ciudadanía. El gobierno democrático de la diversidad, Logroño, Perla, 2012, pág. I27-128. 
Diago Diago, P., «La kafala islámica en España», Cuadernos de Derecho Transnacional, Vol. 2, N I, 2010, págs. I40-164.

FAVRETTO, A. R., Il disordine regolato, strutture, normative e conflitto familiare, Torino, L'Harmattan, I995.

Flaquer, L., Meil, G. Guillén, A.M., Almeda, E., y Escobedo, A., Políticas familiares en la Unión Europea, Barcelona, Institut de Ciències Politiques i socials, 2002.

FoblETS, M.C., «Europa frente a una creciente diversidad de culturas: análisis crítico de algunos desarrollos yexperimentos recientes en el ámbito del derecho de familia», en RUIZ VIEYTEZ, E.J., URRUtia AsúA, G., Derechos Humanos en contextos multiculturales ¿Acomodo de derechos o derechos de acomodo?, Derechos Humanos I8, Zarautz, Diputación foral de Guipuzkoa, 2oio, págs. I4I-I62.

FOBLETS, M.C., Les familles maghrébines et la justice en Belgique (anthropologie jurdique et immigration), Paris, Karthala, I994.

FRESNEDA SIERRA, J., «Redefinición de las relaciones familiares en el proceso migratorio ecuatoriano a España», Migraciones Internacionales, vol. I, n. I, 200I, págs. I35-I44.

Grillo, R., The family in question. Immigrant and Ethnic Minorities in Multicultural Europe, Amsterdam, Amsterdam University Press, 2008.

HERZOG, B., \& HERNÀNDEZ, F., «Un ejemplo de sociologia del desprecio y exclusión discursiva: la metamorfosis de la familia según Kafka», International and Multidisciplinary Journal of Social Sciences, 2(2),20I3, págs. I98-2I7.

HonNETH, A., La société du mépris: vers une nouvelle théorie critique, Paris, La Découverte, 2006.

JAULT-SESEKE, F., Le regroupement familial, Paris, LDGJ, I996.

KOFMAN, E., «Family-related migration: a critical review of European studies», Journal of Ethnic and Migration studies. vol. 30, n. 2, 2008, págs. 243-262.

LA SPINA, E., Familias transnacionales, sociedades multiculturales e integración: España, Italia y Portugal en perspectiva comparada, Madrid, Dykinson, $20 \mathrm{II}$.

LA SPINA, E., «DNA testing for Family Reunification in Europe. An exceptional Resource?», Revista Migraciones internacionales, 22, 6, núm. 3, 2012, págs. 39-74.

LosAno, M.G., La Turchia tra Europa ed Asia: un secolo tra laicismo e Islam, Memoria dell'Accademia delle Scienze di Torino, Classe di Scienze Morali, Storiche e Filologiche, Serie V, Volume 33, Torino, Accademia delle Scienze, 2009.

MCGLYNN, C., «Family reunion and the Free movement of persons in European Law», International Law Forum du droit international, 7, 2005, págs. 159-166.

MCINTOSH, D., «Defining Family: a comment on the Family reunification provisions in the Immigration Act», Journal Law and Social Policy, 3, I988, págs. I04-II5.

MoYA EsCudero, M.: «Derecho a la reagrupación familiar (arts. I6,I7,I8 y I9)», en MOYA ESCUDERO, M. (coord.), Comentario sistemático a la Ley de extranjería (LO 4/2000 y LO 8/2000), Granada, Comares, 200I, págs. 673- 707.

PASCOUAU, Y. Conditions for family reunification under strain. A comparative study in nine EU member states, Bruxelles, European Policy Centre, $201 \mathrm{~s}$.

PERRUCHOUD, R., «Family Reunification», International migration: quaterly review, International Organization for Migration, 27 (4) Dec., I986, págs. 509-524.

POCAR, V., RofAni, P., La famiglia e il diritto, Roma, Editori Laterza, 2008.

QUIÑONES ESCÁMEZ, A., «La protección del menor venido a España en kafala: acogimiento con tutela dativa, y en su caso, adopción», en QuiÑones EsCÁMEZ, A., RodríGUEZ BENOT, A., ZEKRI, H., OUHIDA, J., Kafala y adopción en las relaciones hispano-marroquíes, Madrid, FIIAP, 2009, págs. I57-I97.

SAROlEA, S., Droits de l'homme $t$ migrations. De la protection du migrant aux droits de la personne migrante. Collection du centre des Droits de l'Homme de l'Université Catholique de Louvain, Bruxelles, Bruylant, 2006. 
SOlANeS CoRella, A., «¿Cómo gestionar los flujos migratorios para potenciar la inmigración legal? Un análisis jurídico desde España», Migraciones internacionales, vol. 4, núm. 4, 2008, págs. I36-I72.

Solanes CoRella, A., «Un balance tras 25 años de leyes de extranjería en España: I985-20I0», Revista del Ministerio de Trabajo e Inmigración, 90, págs. 77-IOI.

SOlANes Corella, A., «Human rights and Conflicts in European Multicultural societies», Migraciones Internacionales, vol. 7, núm. I, págs. 70-I00.

SOTO MoYA, M., «Mujer inmigrante marroquí: reagrupación familiar», en RUIZ SUTIL, C. y RUEDA VALDIVIA, R., (coord.), La situación jurídico-familiar de la mujer marroquí en España, Sevilla, Junta de Andalucía. Instituto de la Mujer, 2008, págs. I3I-I54.

STALFORD, H., «Concepts of family under EU law, lessons from the ECHR», International Journal of Law, Policy and Family, 16, 2002, págs. 4IO-434.

SuÁrez-Orozco, C. y SuÁrez-Orozco, M., «Familyhood across borders», MClain, L., Cere, D., What is parenthood?: contemporary debates about the family, New York, Newyork University press, 2013, págs. 279-295.

Susín BetRÁn, R., Fronteras y retos de la ciudadanía. El gobierno democrático de la diversidad, Logroño, Perla, 20I2.

VAN BUEREN, G., «The international protection of family members rights as the 2Ist century approaches», Human Rights Quaterly, vol. I7, I995, págs. 732-765. 